\title{
Planned Study Subject Experience
}

National Cancer Institute

\section{Source}

National Cancer Institute. Planned Study Subject Experience. NCI Thesaurus. Code C93626.

A description of what the study subject can expect to experience over the course of the study, including the sequence and duration of activities. 